\title{
Importance and Characterization of Coffee Berry Disease (Colletotrichum kahawae) in Borena and Guji Zones, Southern Ethiopia
}

Abdi Mohammed* and Abu Jambo

Bule Hora University, Bule Hora, 144, Ethiopia

\begin{abstract}
Coffee (Coffea arabica L.) is one of the most important cash crops in Ethiopia. Coffee Berry Disease (CBD) caused by Colletotrichum kahawae is the severe disease threatening coffee production in most coffee-growing regions of the country. Field survey was conducted in three major coffee growing districts (Abaya, Bule Hora and Kercha) of Borena and Guji zones during 2012 cropping season to determine the incidence, severity and prevalence of CBD. CBD was prevalent in all the surveyed districts with the overall mean incidence and severity of 49.3 and $14.7 \%$, respectively. Laboratory experiment was conducted at Haramaya University to investigate the characteristics of $C$. kahawae and other fungal pathogens associated with coffee berries. The proportion frequencies of infected and non-infected coffee berries were ranged from $24-42$ and $3-21 \%$, respectively. C. kahawae, F. lateritium and Phoma spp. of fungal pathogens were isolated from infected coffee berries with the proportions of $89.2,15.2$ and $3 \%$, respectively. In general, the study revealed high occurrence, distribution and contamination of CBD in the study areas. Therefore, more extensive empirical assessment of the amount of yield loss due to CBD on most grown varieties in the areas and developing or introducing resistant varieties need to have high priority for developing management options which may enhance sustainable coffee production in the country.
\end{abstract}

Keywords: Coffea arabica; Colletotrichum kahawae; Disease intensity; Fungal identifications; Ethiopia

\section{Introduction}

Coffee belongs to the family Rubiaceae and the genus Coffea. The genus Coffea consists approximately 100 coffee species. The two main species of coffee cultivated on a world scale are Arabica coffee (Coffea arabica L.) and Robusta coffee (Coffea canephora L.), which account for about $98-99 \%$ of the world coffee production. In fact, Ethiopia is the only center of origin and diversity of Arabica coffee [1]. Arabica coffee is cultivated in most parts of the tropics, accounting for $80 \%$ of the world coffee market, and about $70 \%$ of the production [2]. Coffee plays an important role in the world economy. It is the second most valuable exported commodity on earth after oil [3]. More than 80 countries in the developing world depend on coffee as a major source of their foreign currency earnings. For instance, coffee generated about US $\$ 13$ billion in 1983 [4], and until 2000, it contributed to $80 \%$ of Burundi's, $55 \%$ of Uganda's and $30 \%$ of Nicaragua's hard currency earnings from exported yields [5].

Coffee is the major source of foreign currency for Ethiopia and contributes more than $35 \%$ of the total export earnings. Thus, it is a cornerstone in the export economy of the country [6]. Its cultivation, processing, trading, transportation and marketing provide employment for millions of people [7]. It is also the defining feature of the national culture and identity, with $44 \%$ of the production consumed domestically [8]. Ethiopian people drink coffee at least three times per day followed to their meals during fasting days.

In Ethiopia, coffee grows over a wide range of agro-ecological zones and geographical regions. Mainly it is grown in the Southern, Southwestern and Eastern parts of the country under different types of production systems. These systems are mostly forest-based traditional coffee production systems which is followed by plantation coffee productions $[9,10]$. The estimated area of land covered by coffee is about 600,000 hectares, and the estimated annual national production of clean coffee is about 350,000 tones [11].
Despite the high production potential and economic importance of coffee; production and productivity of the crop is still limited due to several factors, such as shortage of adaptive cultivars and soil fertility status, diseases, insect pests and weeds. Among these factors, Coffee Berry Disease (CBD) caused by Colletotrichum kahawae, Coffee Wilt Disease (CWD) caused by Gebberella xylarioides and Coffee Leaf Rust (CLR) caused by Hemileia vastatrix are the three most important and destructive diseases threatening coffee production in Ethiopia. However, CBD is the most serious problem of coffee production commonly prevailing in many coffee growing regions including Southern parts of the country. The disease cause a national yield loss estimated to $25-30 \%$, but on susceptible cultivar under favorable environment, $100 \%$ loss could occur $[12,13]$.

Survey data are useful to gain insight in to the occurrence, distribution and relative importance of diseases [14]. In Southern Ethiopia, especially in the Borena and Guji areas, such data, under varying small-scale production situations and systems are lacking. Understanding the association of disease intensity and different management practices will help to identify the most important variables and focus efforts in developing integrated and sustainable management package [14].

Therefore, this study was proposed with the following objectives:

- To determine incidence, severity and prevalence of CBD, and

*Corresponding author: Abdi Mohammed, Bule Hora University, Bule Hora, 144, Ethiopia, Tel: +251-(0)910404497, +251-(0)911903621; E-mail: abdi.mohammed22@yahoo.com

Received February 04, 2015; Accepted March 28, 2015; Published April 04, 2015

Citation: Mohammed A, Jambo A (2015) Importance and Characterization of Coffee Berry Disease (Colletotrichum kahawae) in Borena and Guji Zones, Southern Ethiopia. J Plant Pathol Microb 6: 302. doi:10.4172/2157-7471.1000302

Copyright: ( 2015 Mohammed A, et al. This is an open-access article distributed under the terms of the Creative Commons Attribution License, which permits unrestricted use, distribution, and reproduction in any medium, provided the original author and source are credited. 
- To investigate the characteristics of C. kahawae and other fungal pathogens associated with coffee berries.

\section{Materials and Methods}

The study consisted of two components viz. disease survey to assess occurrence, distribution and relative importance of Coffee Berry Disease, and laboratory test to characterize C. kahawae and other fungal species associated with coffee berries.

\section{Disease survey}

Description of the survey areas: The survey of Coffee Berry Disease (CBD) was conducted in three major coffee growing districts (Abaya, Bule Hora and Kercha) of the Borena and Guji Zones during the 2012 summer cropping season. The Abaya and Bule Hora districts are in the Borena Zone of Oromia Regional State while Kercha is in the Guji. Relatively the areas differ in their land features and cropping systems (Table 1). A total of 27 fields ( 9 from each district) were inspected for disease intensity from 20-25 September 2012 (Table 2). All sample fields belonged to small, private farmers. Each field was visited once.

Disease and crop assessment: From each of the three selected district, three coffee growing peasant associations were selected. From each of the three peasant associations, three coffee fields were randomly selected at intervals of 1-2 km along the main and accessible rural roads and assessed for the disease survey. The assessment was conducted on a total of 10 randomly taken plants within each field. Random selection of the plants for assessment was done by moving in ' $\mathrm{X}$ ' fashion within the field by taking plants at a distance of about 6-8 $\mathrm{m}$ intervals based on the size of the field. Sample size consisting of all the berries in four simple branches of 4-6 plants was reported to have least coefficient of variation in a plot of 100 plants [15]. Based on these, stratified sampling i.e. three pairs of branches from each upper, middle and lower canopy layers of the coffee plant were selected to assess CBD severity. The occurrence and severity of CBD was recorded from each sample plants.

The incidence of the disease within each coffee field was then determined as the percentage of diseased plants out of the 10 assessed plants. Likewise, CBD severity was computed as the average of 10 plants by estimating the percentage of diseased berries (damaged barriers over on all barriers of sampled branch times 100) from each of the plants assessed. It was rated using standard disease scales of 0-6; where, 0: 0\%, 1: $\leq 2 \%, 2: 2-5 \%, 3: 6-10 \%, 4: 11-50 \%, 5: 51-99 \%$, and $6: \geq 99 \%$ of diseased berries. The scores were changed into Percentage Severity Index (PSI) for the analysis using the formula of Wheeler.

$$
P S I=\frac{\text { Sum of numerical rating }}{\text { Number of plant rated } x \text { max imum score of the scale }} \times 100
$$

Disease prevalence was determined as the proportion (\%) of total field assessed for each district. For each field assessed, other diseases of coffee, variety type, and plant age and growth habit were noted (Table 2 and Appendix Table 1). The experiment was structured as nested design (tree was nested under location).

Statistical analysis: The mean incidence and severity of CBD were calculated for each district, peasant association and field. Data were then subjected to nested random effects analysis of variance. The Statistical Analysis System (SAS) Version 9.2 software [16] was used. Significance of associations between incidence and severity on the occurrences of CBD intensity in the plantation coffee populations were examined using simple correlation analysis. Determined Pearson correlation coefficients were used as indices for strength of the association.

\section{Laboratory experiment}

This experiment was carried at Plant sciences laboratory (Haramaya University) to characterize C. kahawae and other fungal pathogens associated with coffee berries. In this study a total of 27 samples of coffee beans, each containing about 50-100 berries were collected from coffee fields of the surveyed areas (i.e. one sample of coffee beans per field, 100 gm per sample).

Fungal isolation from coffee berry: The collected coffee berry samples were premature green berries and partially ripe beans with slightly sunken and dark brown lesions. The diseased berry samples were surface disinfested with Clorox solution of $70 \%$ for three minutes three times consequently and then rinsed with sterilized distilled water twice for $1 \mathrm{~min}$. Totally 15 coffee berries were tested from each sample, five coffee beans by three replications per sample was plated on the prepared media of Potato Dextrose Agar (PDA) and made under $25^{\circ} \mathrm{C}$ for 5-7 days. Frequency of infected and non-infected berry was taken, the contaminated fungal isolates were counted and the proportions of sprouted fungal species were examined as:

$$
\% \text { fungal species }=\frac{\text { Number of isolates fungi }}{\text { Total number of sprouted isolates fungi }} \times 100
$$

Transferring and isolation of $\boldsymbol{C}$. kahawae fungi: This was done in sterile Biological Safety Cabinets (laboratory hood) in order to avoid contaminations of other air borne pathogens. All coffee berries which showed contaminations of fungal growth was counted and recorded as the frequency per location. The fungal colonies of $C$. kahawae and other fungal pathogens species were sub-culturing or transferred to new freshly prepared media of MEA for further identifications by sterilized toothpicks and flamed loops through slightly touching one of the colony and stabbing the center of petriplate according to their species characterizations separately. A new sterile stick was used only for each berry. The name of the isolate and the date were recorded.

Identification of fungal pathogens: Isolates were grown on the prepared medium and incubated at $25^{\circ} \mathrm{C}$ for 5-7 days for proper identifications at species level. Isolates were examined for conidial morphology, conidial lengths, colony size, shape, colors and by their textures (smooth and/or rough). Colony and conidial characters were recorded after 6 to 7 days of growth at $25^{\circ} \mathrm{C}$ in darkness to induce sporulation. Samples of conidia were taken and mounted in water. The conidial shape was observed under a light microscope (Leica Microsystems) and photographs were taken with a Digital camera. For

\begin{tabular}{|c|c|c|c|c|c|}
\hline Zone & District & $\begin{array}{c}\text { Altitude } \\
(\mathbf{m} . \mathbf{a . s .})\end{array}$ & $\begin{array}{c}\text { Rainfall } \\
(\mathbf{m m})\end{array}$ & $\begin{array}{c}\text { Temperature } \\
\left({ }^{\circ} \mathbf{C}\right)\end{array}$ & $\begin{array}{c}\text { Cropping } \\
\text { system }\end{array}$ \\
\hline Borena & Abaya & $1200-2060$ & $900-1400$ & $16-24$ & Varied \\
\hline & Bule Hora & $1300-2600$ & $500-800$ & $15-35$ & Sole \\
\hline Guji & Kercha & $1450-2300$ & $500-1800$ & $15-32$ & Varied \\
\hline
\end{tabular}

Table 1: Characteristic features of the surveyed areas.

\begin{tabular}{|c|c|c|c|c|c|c|}
\hline \multirow{2}{*}{ District } & \multirow{2}{*}{$\begin{array}{c}\text { Altitude } \\
\text { (m.a.s.l) }\end{array}$} & \multicolumn{2}{|c|}{ CBD } & \multicolumn{2}{c|}{ Disease prevalence (\%) } \\
\cline { 3 - 7 } & $\begin{array}{c}\text { Incidence } \\
\text { (\%) }\end{array}$ & $\begin{array}{c}\text { Severity } \\
\text { (\%) }\end{array}$ & CBD & CW & CLR \\
\hline Abaya & 1630 & 53.3 & 21.4 & 100.0 & 33.3 & 11.1 \\
\hline Bule Hora & 1950 & 42.2 & 8.0 & 100.0 & 55.6 & 0.0 \\
\hline Kercha & 1875 & 52.2 & 14.9 & 100.0 & 33.3 & 11.1 \\
\hline Mean & & 49.3 & 14.8 & 100.0 & 40.7 & 7.4 \\
\hline
\end{tabular}

CBD: Coffee Berry Disease, CW: Coffee Wilt, and CLR: Coffee Leaf Rust.

Table 2: Mean incidence, severity and prevalence of CBD and other diseases of coffee plant in surveyed areas during 2012 cropping season. 
each isolate, length and width of 100 randomly chosen conidia were measured through calibrating the ocular and stage micrometer of microscope by using the image analysis program Leica Qwin Standard (Leica Microsystems) of $40 \times$ objectives. Then identified isolates cutting out plugs from the plates using sterilize plunger in to vials containing $2.5 \mathrm{ml}$ of sterile distilled water. The vials were tightly closed, correctly labeled and stored at temperature of between $4-8^{\circ} \mathrm{C}$ pending for any further mycological analysis.

Data analysis: Data on the frequencies of coffee berry infection by C. kahawae and other associated fungal species for samples collected from different districts of peasant associations across the farmer's fields were analyzed by SPSS 16.0. Ink models [17]. The proportions of infected berry by each fungal colony were also determined. All data on identifications and characterizations of C. kahawae and other fungal pathogens were analyzed using descriptive statistics.

\section{Results and Discussion}

\section{Importance of CBD in Borena and Guji zones}

Incidence and severity of CBD: A total of 27 fields were surveyed in three districts of Borena and Guji Zones. Disease incidence of CBD in the fields was computed for peasant associations, districts and the entire study areas. The indicated analysis shows that CBD incidence among peasant associations and districts appeared similar (Appendix Table 2). Mean incidence ranged from $42.2 \%$ in Bule Hora fields to 53.3\% in Abaya. The overall mean incidence at district level was $49.3 \%$ within the surveyed areas (Table 2).

Like disease incidence, severity of CBD in the fields was also computed for peasant associations, districts and the entire study areas. There were no observed significant variation in disease severity among the surveyed peasant associations and districts (Appendix Table 3). Mean severity ranged from $8.0 \%$ in Bule Hora fields to $21.4 \%$ in Abaya. The overall mean severity at district level was $14.8 \%$ within the surveyed areas (Table 2). Generally, this level of disease intensity might be due to the use of homogeneous coffee cultivars and crop management practices in the surveyed areas (Appendix Table 4). The spread and scale of epidemics was suggested to be due to the use of a limited number of varieties and the predominant self-fertility of $C$. arabica and uniform cultural practices over a long period. The importance of CBD might also be judged from the high cost incurred to control the disease using chemicals [13]. Therefore, the use of locally adapted and high yielding coffee cultivars with high level of resistance to CBD is of paramount importance in Arabica coffee production in different regions.

Prevalence of CBD and other diseases of coffee plant: The computed prevalence of CBD was $100 \%$ in each of the surveyed district with an overall mean of $100 \%$. In addition to CBD, prevalence of other coffee diseases, such coffee wilt (caused by Gibberlia xylorioids) and Coffee Leaf Rust (caused Hemileia vastatrix) were recorded for each district. The overall mean prevalence of coffee wilt and leaf rust were 40.7 and $7.4 \%$, respectively, within the entire study areas (Table 2). Previously it was also reported that CBD, coffee wilt and Coffee Leaf Rust are the three major economically important diseases that limit coffee production in Ethiopia [12,13].

Simple linear correlations analysis between CBD incidence and severity using mean values revealed the existence of significant $(\mathrm{P}<0.001)$ interrelationships. Significant positive correlation was exhibited between CBD incidence and severity $(\mathrm{r}=0.49 ; \mathrm{P}=0.001)$. Considering incidence as predictor variable and severity as response and fitting linear model explained $39.0 \%$ of the variations.

\section{Frequency of coffee Berry contaminated and fungal occurrence}

A total of 27 samples were collected from 27 farmers' coffee fields in three districts of Borena and Guji Zones. The frequency of coffee berry contamination with the fungal pathogens across the districts within the peasant associations shows that the minimum proportions of infected berry ranges from $24 \%$ in samples from Kercha to the maximum of $42 \%$ from Abaya and Kercha districts, whereas the proportions of noninfected berry ranges from $3 \%$ to samples from Abaya, Bule Hora and Kercha districts up to $21 \%$ from Kercha district (Figure 1 and Appendix Table 5).

This study confirm that the coffee berry samples collected from Abaya was highly contaminated compared to Bule Hora and Kercha districts. It was infected more than $15 \%$ and $24 \%$ from Bule Hora and Kercha districts, respectively while sample from Bule Hora was contaminated 9\% more than Kercha district. This may be due to several factors like; common coffee variety which are grown in the surveyed areas, altitude of the district, adopted cultural practice, weather conditions of the area, presence of the fungal races and other factors,

\begin{tabular}{|c|c|c|c|}
\hline Districts & C. kahawae & F. lateritium & Phoma spp. \\
\hline Abaya & $35.33 \pm 2.082$ & $5 \pm 4.6$ & $1 \pm 1.73$ \\
\hline Bule Hora & $36 \pm 3$ & $2 \pm 3.46$ & $0 \pm 0$ \\
\hline Kercha & $27.67 \pm 6.81$ & $5.33 \pm 1.16$ & $1 \pm 1.73$ \\
\hline Total & $33 \pm 5.57$ & $4.11 \pm 3.33$ & $0.67 \pm 1.32$ \\
\hline
\end{tabular}

Means \pm Standard deviations

Table 3: Frequency of fungal species from coffee berry samples across the districts.

\begin{tabular}{|c|c|c|c|}
\hline Zones & Districts & Fungal species & \% of berry contaminated \\
\hline \multirow{3}{*}{ Borana } & \multirow{3}{*}{ Abaya } & C. kahawae & 85.7 \\
\cline { 3 - 4 } & & F. lateritium & 11.9 \\
\cline { 3 - 4 } & & Phoma spp. & 2.3 \\
\cline { 3 - 4 } & \multirow{3}{*}{ Bule Hora } & C. kahawae & 89.2 \\
\cline { 3 - 4 } & & F. lateritium & 10.8 \\
\cline { 3 - 4 } & & Phoma spp. & 0 \\
\hline \multirow{3}{*}{ Guji } & \multirow{3}{*}{ Karcha } & C. kahawae & 81.8 \\
\hline & & F. lateritium & 15.2 \\
\hline & & Phoma spp. & 3 \\
\hline
\end{tabular}

Table 4: Percentages of infected berry by fungal isolates from those three districts.

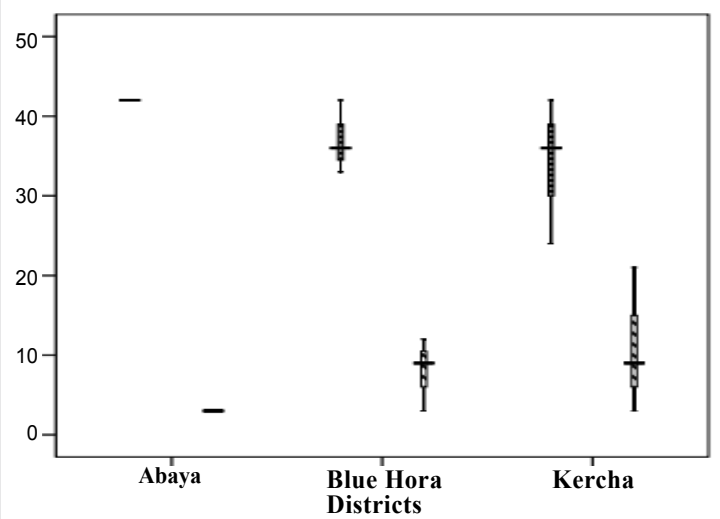

贵 INFB

Figure 1: Frequency distributions of infected and non-infected coffee berry contaminations with fungal pathogens $(\mathrm{N}=45)$ in the study areas. 
the assortments of such scenario may create a favorable condition for the contamination of coffee berry with the diseases.

Coffee tree as a monoculture is harbor for several fungal disease where ever it was grown such as, Coffee Leaf Rust (Hemileia vastatrix), Coffee Berry Diseases (C. kahawae), black rot (Corticium koleroga), brown eye spot (Cercospora coffeicola), anthracnose $(C$. gloeosporioides), American leaf spot (Mycena citricolor), Coffee Wilt Diseases (Gibberella xylarioides), dieback (Phoma species) and pink disease (Contricium salmonicolor) [18]. However, in Ethiopia coffee (Coffea arabica L.) plants are highly infected by numerous diseases that reduce its production and productivity significantly, those are; CBD, rust, vascular wilt, bean darkening, root rot, damping off and others, among these diseases CBD is the major top diseases by causing a yield loss of $24-30 \%$, but sometimes it reduce yield loss of $50-100 \%$ where there is no any management options [19].

In the current study, based on the morphological characteristics (macroscopic and microscopic cultures induces) three different genera of fungal species were crop up from the tested samples of coffee berries. There are C. kahawae, F. lateritium and Phoma species (Table 3 and Figure 2). The basic keys for identification of these fungi were based on the growth rate, colony culture and shape and types of conidia (lengths of conidiophores) according to [12,20]. (The distinct features of each fungal pathogen isolated from coffee berries were mentioned under section 3.3). When all collected coffee berry samples were analyzed at district levels the frequency distributions of different fungal species isolated from the diagnosed beans were significantly varied at $(\mathrm{p}<0.05)$ (ANOVA table, Appendix Table 6).

The proportions of fungal species from collected coffee berry samples in across the districts of two zones from the infected beans were as follows (Table 4).

In this result, isolates of C. kahawae species was highly contaminated to coffee berry samples obtained from all over the surveyed areas. The proportions of isolates ranged from $81.8 \%$ of samples from Kercha to 89.2\% of Bule Hora districts, while other Colletotrichum species were not isolated from the diagnosed berries. The samples from Bule Hora and Kercha districts were highly contaminated by CBD (C. kahawae) followed by Fusarium species of $F$. lateritium isolates, which was ranged, from $10.8 \%$ of samples from Bule Hora to $15.2 \%$ of Kercha district. Both C. kahawae and F. lateritium species were isolated from samples obtained throughout the surveyed regions. In contrary to this, other pathogen also known as Phoma spp. was less contaminated to

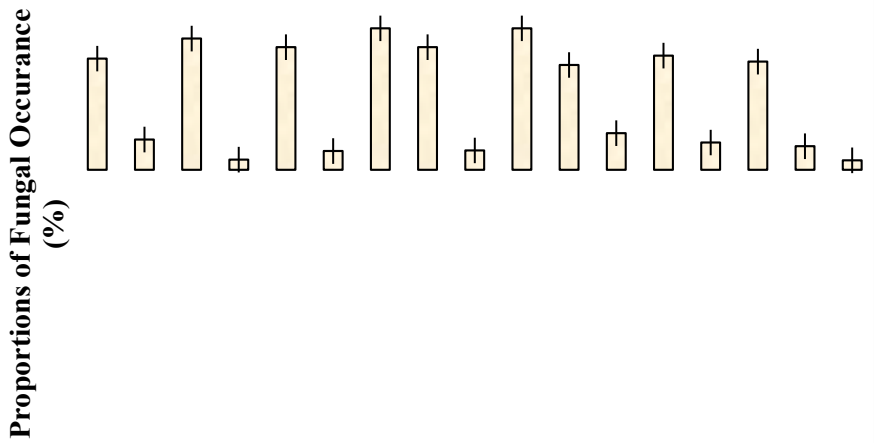

Figure 2: Proportions of fungi isolated from coffee berry across the districts with in the PAs of the two zones of surveyed districts. Abaya; Gangua, Foge and Hafursa Waro. Bule Hora; Saraji Elabada, Kilenso Makanisa and Burka Ebala. Kercha; Guracha Jeldu, Banko Guduba, and kercha Inshe. coffee berry samples collected from Abaya with the proportions of 2.3\% and Kercha districts 3\% and not isolated to samples from Bule Hora district. Perhaps the environmental conditions and agronomic practices of Bule Hora district does not permit for the pathogens, may be the ecology of Abaya and Kercha districts are encouraging factors for Phoma species.

However, the fungal species contaminations to berries from each PA were ranged from $6.7 \%$ by Phoma species to $100 \%$ by C. kahawae from diagnosed samples at kebele levels $(\mathrm{N}=3)$.

The previous reports on associations of $F$. lateritium species on coffee berry were limited in Ethiopia, whereas species of $F$. xylarioides the wilting pathogens on Coffea arabica was first observed in Ethiopia (in Keffa province in 1957) [21]. Such studies were showed that, previously most isolates of Fusarium species were associated with coffee wilt; however, in the current study F. lateritium species was isolated from green coffee berry samples. It was supported by some research which stated that, isolates of Clades IIA and IIB of the F. lateritium isolated from citrus and green coffee berry in New Caledonia, New Zealand and Philippines [22].

Phoma species was reported as an important disease of coffee die-back which was occurring worldwide [23]. It was also a disease attacking leaves, branches and fruits of fruit crops or (green berries) of coffee plant and mainly occurs in nurseries and field plantations. The pathogen inhabit areas such as; higher altitudes with low temperature, high humidity and cold winds. It needs water for infection $[18,23]$. In this investigation, isolates of this species was isolated from samples of Abaya and Kercha districts which has higher altitudes with low temperatures accompanied with high humidity and cold winds during the survey and sample collection times, this scenario perhaps create a conducive environmental conditions for the out breaks of Phoma species associated to coffee green berry.

There was limited report on contamination of coffee berry by Phoma species in our country even in the world; however, in Kenya, there is a report on coffee endophytes after surface-sterilizing healthy leaves, pedicels, stems, and green berries with a mercuric chloride saponin solution, and He diagnosed Coffee Berry Disease, Colletotrichum coffeanum, (currently known as C. kahawae Waller and Bridge), and species of Phoma and Phomopsis [24]. This result was agreed with our study because samples collected during the survey were green berries. Another report from Puerto Rico mentioned Botryosphaeria, Colletotrichum, Guignardia, and Xylaria species as fungal endophytes in coffee plants $[25,26]$ and identified 13 Penicillium species as endophytes in C. arabica, Coffea congensis, Coffea dewevrei and Coffea liberica, including Penicillium coffeae, a new species described by [27]. Another report in Ethiopia declared that, C. kahawae and $C$. gloeosporioides were the only two species of fungus isolated from coffee tissue of samples collected from Habro and Kuni districts in Hararghe region [28].

Identification of fungal species associated with coffee berriesIdentification of $C$. kahawae: In this study, the first species isolated from the collected coffee berry sample was $C$. kahawae. The major distinction currently separates $C$. kahawae from the other species of Colletotrichum was the old colony of $C$. kahawae produce pale yellowish to pinkish with dense whitish-grey aerial mycelium and a few bright orange conidial masses on the tips of the active growing hyphae on MEA media (Figure 3). The young colony produce grey, becoming grey to dark, olivaceous grey, dark greenish in reverse side of plates. The previous report reveals, a colony of $C$. kahawae isolated 


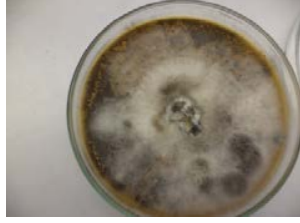

A, Front

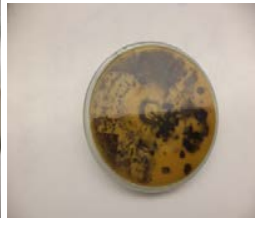

B, Reverse

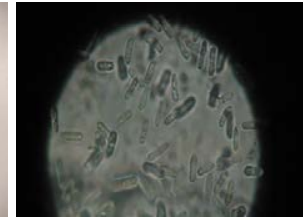

C, Conidial Features
Figure 3: Species of C. kahawae isolated from coffee berries. A and B, colony features and $\mathrm{C}$, conidial features.

from Hararghe coffee shows the same color and ability to form saltation but some colonies demonstrate dark mycelium while other produces grayish mycelium [28].

The colony had also slow growth rate compared to other species. The cultures produce perithecia ascocarp. The conidial shape was hyaline, straight and generally cylindrical with rounded ends and biguttulates (Figure 3C). For further confirmations, about 100 conidial of $C$. kahawae were taken from different colonies of 8 days old cultures and measured for the length under light microscopes (Leicia), by calibrating the ocular micrometer and stage micrometer (Appendix Table 7). The length and width of conidia was varying from 7.5-18 $\times 3-5$ $\mu \mathrm{m}$ respectively, this result was exactly agreed with the work of $[29,30]$, but Colletotrichum fructicola produces smaller conidia as compared to C. kahawae which ranges from 9.7-14 $\times 3-4.3 \mu \mathrm{m}$ in length and width respectively.

Identification of $F$. lateritium: Based on growth and morphology of isolates, $F$. lateritium was produce colonies of white and light mycelia by both sides of plates on the PDA and MEA media, and later it was become colorless. The report from Uganda demonstrates, F. lateritium colony isolates were examined morphologically on PDA and MEA. Colonies on PDA and MEA were white, pale to colorless after 3 days and pale orange 4-14 days later depending on the isolate $[22,31]$. The orange pigmentation was more intense in the center of the colony and faded to pale orange to white at the growing margin then becomes colorless. The same morphological features of the colony were examined in the current study.

For more description of the species 100 spore containing conidiophores were measured the length by light microscopes (Leicia), by calibrating the ocular micrometer and stage micrometer (Appendix Table 6), and record the lengths, and it was vary from 18-34 $\mu \mathrm{m} . F$. lateritium conidia measuring to $19-42 \mu \mathrm{m}$ in length according to the number of septa and 3-5 $\mu \mathrm{m}$ in width, sometimes the maximum conidial lengths was up to $82 \mu \mathrm{m}$ [32]. However, the maximum length very far apart, it likely due to some factors likes media nutrient contents, incubation temperatures or other factors which induces for the growth of the conidiophores.

Identifications of Phoma species: Phoma species is yet another ubiquitous, cosmopolitan fungus which is commonly found in soils. As a known plant pathogen, it may also be recovered from infected plant materials of different vegetables, fruit crops and green coffee berry. It may be found in the laboratory as an environmental contaminant [33]. However, based on conventional identifications which conducted in the current study, it was a rapidly growing fungus which usually reaches maturity within five days. It was fungal isolates produce dark brown to black mycelia with tiny conidiophores on MEA and PDA media and also not feasible to measure the length and width of conidiophores under light microscopes like another results of C. kahawae and F. lateritium. In Kenya, report that, green coffee berries were infected by Phoma species which demonstrate mycelium colony of brown to dark colors morphologically with fine conidiophores [24]. Another study confirm that, colony colors of Phoma species ranged from olivaceous green to dark brown or black, the reverse was brown to dark brown to black with some species producing a diffusible reddish-brown pigment and colony growth rate was similar for all Phoma isolates in culture media of Oat Meal Agar (OMA) and MEA with the conidial length ranged from 1.6-3 $\mu \mathrm{m}$ which is very fine and smaller [33].

\section{Summary and Conclusions}

Coffee plant is a major cash crop, which earns a hard currency for all growing countries on the entire world especially for African developing countries. In Ethiopia, coffee plays a vital role to maintain the livelihoods of small scale farmers and creates a major job opportunity for millions of peoples. It is successfully produced under rain fed conditions in different climatic regions of the country by small scale farmers, private investors, and state enterprises. In spite of the high production potential and economic importance; its production and productivity is constrained by several abiotic and biotic factors. Among biotic factors, $\mathrm{CBD}$ is one of the most severe coffee diseases in most coffee-growing regions including Borena and Guji areas of the county, where further information on the occurrence, distribution and relative importance of the disease and its characterization are lacking. Therefore, this study was undertaken to determine the incidence, severity and prevalence of CBD, and investigate the characteristics of C. kahawae and other fungal pathogens associated with coffee berries.

In the present work, field surveys were conducted in three major coffee growing districts (Abaya, Bule Hora and Kercha) of Borena and Guji Zones of Oromiya Region by examining and recording of several coffee diseases. The survey revealed that $\mathrm{CBD}$ was prevalent in all the surveyed districts. The overall mean incidence and severity at district level were 49.3 and $14.8 \%$, respectively. Perhaps, this spread and scale of epidemics could be due to the use of a limited number of varieties and uniform cultural practices in the entire study areas.

Three fungal pathogens (C. kahawae, F. lateritium and Phoma $s p p$.) were isolated from coffee berries by diagnosing the berries based on conventional methods (cultural and morphological features). A molecular technique was not conducted for this work, since it needs higher costs. Among the three fungal pathogens, the minimum and maximum proportions of occurrences were recorded from C. kahawae isolate (81.8-89.2\%) followed by F. lateritium (10.8-15.2\%) and Phoma spp. (2.3-3\%) from all the districts, whereas the proportions of infected were ranged from $6.7-100 \%$ in the field levels. In general, the present study revealed high occurrence and distribution of CBD in the study areas. Thus, empirical assessment of the amount of yield loss due to $\mathrm{CBD}$ on most grown variety in the areas and developing or introducing resistant varieties need to have high priority.

\section{Acknowledgement}

We would like to acknowledge the assistances of Borena and Guji Zones Agricultural Office for their kind collaboration in providing necessary information during survey work. The authors also thank Haymanot Bezuneh (Haramaya University, Plant Pathology Lab.) for her assistance in laboratory works. Our special appreciation and deepest thanks go to Bule Hora University for funding the study.

\section{References}

1. Anthony F, Bertrand B, Quiros O, Lashermes P, Berthaud J, et al. (2001) Genetic diversity of wild coffee (Coffea arabica L.) using molecular markers. Euphytica 118: 53-65.

2. Woldemariam T, Denich M, Teketay D, Vlek PLG (2002) Human impacts 
Citation: Mohammed A, Jambo A (2015) Importance and Characterization of Coffee Berry Disease (Colletotrichum kahawae) in Borena and Guji Zones, Southern Ethiopia. J Plant Pathol Microb 6: 302. doi:10.4172/2157-7471.1000302

on Coffea arabica L. genetic pools in Ethiopia and the need for its in situ conservation. In: Engels JMM, Rao VR, Brown AHD, Jackson MT (eds.) Managing Plant Genetic Diversity. AB International/IPGRI, Rome. pp. 237-247.

3. Pendergrast $M(2010)$ Uncommon grounds: the history of coffee and how it transformed our world. Basic Books, New York, USA

4. Cannell MGR (1983) Coffee. Biologist 30: 257-263.

5. Oxfam (2002) Bitter coffee: how the poor are paying for the slump in coffee prices. Oxfam International, London.

6. FAO/WFP (2010) Special report FAO/WFP crop and food supply assessment mission to Ethiopia.

7. EEA (Ethiopian Economic Association) (2001) Annual Report on the Ethiopian Economy.

8. Mayne R, Tola A, Kebede G (2002) Crisis in the birth place of coffee, Oxfam International research paper, Oxfam International.

9. Workafes WT, Kassu K (2000) Coffee production systems in Ethiopia Proceedings of the workshop on the control of coffee berry disease (CBD) in Ethiopia. (GhionHotel), 13-15 August 1999, Addis Ababa Ethiopia, pp. 99-106.

10. Taye K, Tesfaye S (2002) Organic coffee production: hope for small-scale farmers in Ethiopia. Proceedings of the 19th International Conference on Coffee Science (ASIC), May 14-18, 2001, Trieste, Italy.

11. Teshome A, Kebede E, Kebede K (2008) Coffee Development and Marketing Improvement Plan. In: Proceedings of A National Work Shop Four Decades of Coffee Research and Development in Ethiopia. 14-17 August 2007, EIAR, Addis Ababa, Ethiopia, pp. 375-381.

12. Biratu T (1995) Studies on Colletotrichum population of Coffea arabica L. 74 in Ethiopia and evaluation of the reactions of coffee germplasms. Doctoral Dissertation. Hohen Landwirtschaftlichen Fakultat der Rheinschen FriedrichWilelms-Universit t Zu Bonn, p. 231.

13. Eshetu D, Teame G, Girma A (2000) Significance of minor coffee diseases of Coffea arabica L. in Ethiopia; a review. Proceedings of the workshop on control of coffee berry disease in Ethiopia, 13-15 August 1999, Addis Ababa, Ethiopia, pp. 58-64.

14. Rusuka G, Buruchara RA, Gatabazi M, Pastor-Corrales MA (1997) Occurrence and distribution in Rwanda of soil borne fungi pathogenic to the common bean. Plant Disease 8: 445-449.

15. Kushalappa AC (1989) Biology and epidemiology. In: Kushalappa AC, Eskes $A B$ (eds.) Coffee rust: Epidemiology, Resistance and Management; CRC Press Inc, Florida, pp. 13-80.

16. SAS (Statistical Analysis System) software (2009) Version 9.2.Inc. Carry, North California, USA.

17. Peck R (2005) SPSS Manual for Introductory Statistics.
18. Anna-Elisabeth (2005) Fungal endophytes diversity in coffee plants from Colombia, Hawai'i, Mexico and Puerto Rico.

19. EARO (Ethiopian Agricultural Research Organization) (2003) Facilitating the Implementation and Adoption of Integrated Pest Management (IPM) in Ethiopia. Melkassa Agricultural Research Center. Planning Workshop 13-15 October 2003. Economic botany 12: 111-139.

20. Gassert WL (1979) Research on coffee berry disease in Ethiopia: Epidemiology and control. GTZ, Eschborn, p. 65.

21. Kranz J, Mogk M (1973) Gibberella xylarioides Heim et Saccas on arabica coffee in Ethiopia. Phytopath Z 78: 365-366.

22. Gerlack W, Nirenberg HI (1982) The Genus Fusarium-a Pictorial Atlas. BerlinDahlem: Paul Parey, p. 406.

23. Lutzeyer HJ, Pülschen L, Compart W, Scholaen S (1994) Recent developments in plant protection for plantation crops as exemplified by coffee" bmz, p. 144

24. Rayner RW (1948) Latent infection in Coffea arabica L. Nature 161: 245-246.

25. Santamaría J, Bayman P (2005) Fungal epiphytes and endophytes of coffee leaves (Coffea arabica). Microb Ecol 50: 1-8.

26. Vega FE, Posada F, Peterson SW, Gianfagna TJ, Chaves F (2006) Penicillium species endophytic in coffee plants and ochratoxin A production. Mycologia 98: $31-42$

27. Peterson SW, Vega FE, Posada F, Nagai C (2005) Penicillium coffeae a new endophytic species isolated from a coffee plant and its phylogenetic relationship to $P$. fellutanum, $P$. thiersii and $P$. brocae based on parsimony analysis of multilocus DNA sequences. Mycologia 97: 659-666.

28. Biratu T, Hulluka M (1989) Colletotrichum species associated with coffee berry disease in Hararge. Eth J Agri Sci 11: 1-6.

29. Waller JM, Bridge PD, Black R, Hakiza H (1993) Characterization of the coffee berry disease pathogen, Colletotrichum kahawae sp. nova. Mycological Research 97: 989-994.

30. Prihastuti H (2009) Characterization of Colletotrichum species associated with coffee berries in northern Thailand. Fungal Divers 39: 89-109.

31. Geiser DM, Lewis Ivey ML, Hakiza G, Juba JH, Miller SA (2005) Gibberella xylarioides (anamorph: Fusarium xylarioides), a causative agent of coffee wilt in Africa, is a previously unrecognized member of the $G$. fujikuroi species complex. Mycologia 97: 191-201.

32. Booth C (1971) The Genus Fusarium. Surrey, England: Commonwealth Mycological Institute, p. 237.

33. Boerema GH, Jde Gruyter ME, Noordeloos, Hamers MEC (2004) Phoma Identification Manual: Differentiation of Specific and Infra-specific Taxa in Culture. CABI Publishing. Wallingford, Oxford shire, UK. 